\title{
Humiliation's media cultures: On the power of the social to oblige us
}

\section{Sarah Cefai}

Goldsmiths, University of London, UK

\begin{abstract}
Humiliation, which Silvan Tomkins paired with shame ('shame-humiliation'), has not received much attention in queer, feminist and cultural analysis. This article addresses this omission by putting forward an account of humiliation's eventful 'structure of feeling'. In line with Raymond Williams' original conception, and in conversation with affect studies, my account links humiliation's structure to the broader socio-political tensions it articulates: especially, the tension between individualisation and collective social experience within neoliberalism. The cultural economy of reputation in particular reveals how, from within the eventful structure of humiliation, we become attuned to the social as that which affectively obliges us. By mediating the affective obligation of the social, media cultures train us in an affective sociality. My analysis questions the deeper reasoning that subtends humiliation and the repercussions of the affective obligation of the social for how we think about culture, identity and power in the context of networked media.
\end{abstract}

\section{Keywords}

Affect, humiliation, identity, injury, shame, social media, social status

[W]e all have ticking away within us something we fear will badly harm our reputation if it got out . . . even in these days of significant over-sharing we keep this particular terror concealed, like people used to with things like masturbation before everyone suddenly got blasé about it

\section{Corresponding author:}

Sarah Cefai, Goldsmiths, University of London, London SEI4 6NW, UK.

Email: s.cefai@gold.ac.uk 
online. With masturbation, nobody cares. Whereas our reputation - it's everything. (Ronson, 2015: 27-28)

Take a feather pillow, cut it open, and scatter the feathers to the winds. (Hasidic parable)

In this essay, we will come to take seriously the proposition that 'our reputation is everything' - from the vantage point of humiliation. While data are the economic language of digital culture, reputation is central to the cultural currency of networked and social media exchange. Online modalities of expression combine the articulation of a person's social status, how someone becomes known to others, the impression one gives off, the selling of the self and so on, in a cultural economy of reputation. This combination is less the effect of people's subjective intentions, and more a reflection of the ways in which cultural formation of digital media hinges upon the mediation of the relation between individual and collective identities (Papacharissi, 2011). Within digital culture, personal and impersonal, individual and collective identities are mediated alike, as the logic of reputation criss-crosses organic and inorganic, human and non-human entities. Reputations put something at stake, and in the case of individual identities, they put at stake something of ourselves. Reputations can make or break us, as well as make or break the worlds we are living. Humiliation, this essay goes on to argue, casts into action relations between reputation, sense of self and our capacity to be in the world. As a thoroughly social phenomenon, humiliation speaks to our underlying affective obligation to one another and the world we are living. I hence claim that because humiliation tells us about the power of the social to oblige us, humiliation also tells us about power and identity. I will further argue that contemporary media cultures are not simply fetishising humiliation as a textual thematic, such as in online shaming by individuals or the tabloid press, but are constitutively and substantively linked to humiliation in their mediation of our affective obligation to the social. As such, I put forward an exploration of why this nexus of relations, which I will describe as humiliation's affective structure, has become all pervasive in times of precarity and 'networked misogyny' (Banet-Weiser, 2018).

Learning of my interest in humiliation, more than one colleague has recommended journalist Jon Ronson's (2015) popular book, So You've Been Publicly Shamed. Colleagues' interest in the culture of shaming is unsurprising given the toxic combination of academic precarity and performance culture. In academic circles no less, the 'terror of being found out' ticks away (Ronson, 2015: 27). This terror presents a somewhat ironic fate, given the scholarly promise of notions such as intellectual insight and integrity. Our disciplinary investment in such notions sets up our fallibility in the event of their failure. Just think of the scientist Matt Taylor crying as he apologises for the 'big mistake' of wearing a shirt that 'offended many people' while reporting live on the Rosetta space mission (European Space Agency, 2014,). Or how University College London pressured the Nobel laureate Tim Hunt to resign for making a clichéd joke on the conference scene, about girls in science labs falling in love and crying (McKie, 2015). We know these examples because of their traction online, and so perhaps too because of the gender and cultural standing of their subjects and institutions. Just as we know as well how the discourse on 'student experience' magnifies anxieties around student complaint, thanks to the economic precarity of universities reliant on student fee income. 
Such examples point immediately to a link between humiliation, precarity and a heighted media discourse on gender relations.

Certainly masquerade arrives on the scene of academia at a particular moment - as 'the market metrics of our time' configure their subjects 'as self-investing human capital', and as knowledge comes to be valued only in terms of its 'capital enhancement' (Brown, 2015: 177): 'imposter syndrome' arrives as our profession is humiliated. The worry that we do not live up to others' expectations of us further incites a structure of humiliation - a patterning of expectation and response. Our subjection to incompossible demands in the classroom is lived out in this worry, as the "saturation of university life by neoliberal rationality, metrics and principles of governance' (p. 198) diminishes our labour power. What was once a potential for 'democratic citizenship', collectively held and cradled for wider society, is territorialised by a version of 'human capital' (p. 184) that is both technocratic and populist. Just such neoliberal transformations of work, including the rise of entrepreneurialism, casualisation, performance culture and 'networking and selling the self' (McRobbie, 2015: 26), extend the reach of capitalism into 'the profane banality of the everyday' (Lash, 2007: 66). In this articulation of capitalism - the 'industrialisation of culture' and the "cculturification" of industry' (p. 74) - we are increasingly beholden to the cultural circulations of reputation. As Scott Lash and Celia Lury (2007) earlier argued, brand capitalism generates value 'via the logic of difference' (p. 5). Like the brand, a reputation consists in an 'abstract, singularity' (p. 6); an everproliferating transversal individuality interlinking the 'macro' and 'micro' logics of investment, the corporation and other capitalist terms. As the integrity of liberal (public, accountable, democratic, etc.) institutions is hollowed out, the identificatory phantasma of reputation gains prominence.

Humiliation is a 'traumatic shame', defined by Kathleen Woodward (2000) as 'shame that cannot be transformed into knowledge' (p. 213). The knowledge that traumatic shame cannot be transformed into is self-knowledge and shame that cannot be transformed is traumatic. In humiliation, the (former) self is not recoverable from the (later) debris of their humiliation - something is shamed out of existence. '[T] hought of and remembered by their humiliation . . . [people] become their humiliation' (Burton, 2014). Access to a prior social fabric dissolves. In the trauma of humiliation, the subject 'no longer finds traction in the ways of being that had provided continuity and optimism for her' (Berlant, 2008: 4). In humiliation, you endure the 'shattering realization that your most dearly held self-perceptions and bases of self-respect have been torn down' (Saurette, 2005: 1). This shattering realisation nonetheless instantiates the value system that had generated such perceptions, particularly those normative pretensions of identity that distinguish classed, raced and gendered forms of social interaction and patterns of social belonging. As 'a disciplinary force' (p. 5) then, humiliation mobilises regulatory fictions about the self to injure the subject's sense of self-worth and withhold the possibility of self-repair. These are inversions of the same fictions that give us a sense of self to begin. Yet, in its aftermath, humiliation 'leaves little basis to refashion an affirmative subjectivity' (p. 8). As Silvan Tomkins said of shame, 'loss of face [can] be more intolerable than loss of life' (Tomkins in Sedgwick and Frank, 1995: 136). In humiliation, one witnesses one's own life coming to an end, from within the ongoing necessity of living. 
Situated within affect studies, I examine humiliation not as epiphenomenal, or as an expression of a psychologised subjectivity, but as a 'structure of feeling'. According to Raymond Williams (1977) and his readers, the concept of feeling as having a structure places 'the historical present in the affective presence of an atmosphere that is sensed rather than known and enacted, a space of affective residue that constitutes what is shared among strangers' (Berlant, 2015: 194). I am interested in how humiliation constitutes just such a space of residue - in what is constituted by humiliation's 'singularity of feeling' (Cefai, 2012: 18). Humiliation is understood as a composite term, defined by an internal set of subjective and affective relations, but also by a thoroughly social and aesthetic patterning of affect. To theorise the singularity of humiliation, I offer a close reading of how humiliation is singularly lived according to such characteristics across a range of media examples. My analysis of humiliation looks beyond 'the experience we associate with a typical emotional event' (Berlant, 2008: 4), to the structural elements in play for humiliation to eventuate. As such, this essay seeks to (1) draw attention to and account for the prevalence of humiliation as a textual thematic within contemporary media cultures and (2) consider the implications of digitally and affectively networked humiliation for how we theorise relations among the social, power and identity.

\section{The everyday of humiliation's media culture}

Pictures hang about on Google like a gypsy fucking curse. There's no cure for the Internet. It would never go away. It'd be glued to your name; a fucking stain on you. I'd hang myself if that was me. Crack my fucking neck at the first opportunity. (Hector [Jerome Flynn], 'Shut Up and Dance', Black Mirror)

You think that everyone in the world is out to humiliate you. (Marnie [Allison Williams], Girls)

My analysis of the everyday of humiliation's media culture begins with a consideration of how humiliation is thematised in televisual character and narrative development. Netflix's popular and critically acclaimed Better Call Saul (2015-present) offers a telling example of how a TV series can hone the significance of humiliation within the contemporary social fabric. From the vantage point of television, humiliation is a social drama ripe for the screen - a drama of the circumstantial interdependencies and affective indeterminacies that foreground the relationship between identity and the rules of familial, institutional and cultural inclusion. Interdependency and indeterminacy provide dramatic suspense: humiliation as a structure of risk is made tangible in a range of ways. For example, the risk of injury to one's dignity is made tangible in characters' perpetual worry (such as, worry over 'the terror of being found out'). In the case of a TV series, this structure includes the worry of the audience. The audience of Better Call Saul worries the protagonist Jimmy McGill (Bob Odenkirk), as well as indulges in the thrill of his play with social boundaries and categories. It is the hypocrisy of social status that Jimmy iconoclastically games, but not without risking his own status.

Better Call Saul examines our culture of humiliation by exploring the predicament of living with a 'spoiled identity' (Goffman, 1963). Throughout the series, the notion of a spoiled identity plagues Jimmy, later known as Saul (revealed in this episode to be a play 
on the expression 'It's-aul good!'). This ongoing thematising of humiliation is crystallised in the last episode of Season 4 of Better Call Saul. Party to a recruitment process that rejects Christy Esposito's (Abby Quinn) application for a law scholarship, Jimmy chases after Christy to address the young applicant directly. Jimmy urges Christy to defy her reputation, to take justice into her own hands:

You didn't get it. You're never going to get it. They dangle these things in front of you; they say you've got a chance. But, I'm sorry: it's a lie, because they'd already made up their mind and they knew what they were going to do before you walked in the door. You made a mistake and they are never forgetting it. As far as they're concerned, your mistake is just, it's who you are. It's all you are. I'm not just talking about the scholarship here. I'm talking about everything. I mean, they'll smile at you, they'll pat you on the head, but they are never, ever letting you in. (Beat) But listen. Listen. It doesn't matter. It doesn't. Because you don't need them. They're not gonna give it to you? So what. You're gonna take it. You're gonna do whatever it takes, do you hear me? You are not gonna play by the rules. You're gonna go your own way. You're gonna do what they won't do. You're gonna be smart. You are gonna cut corners. And you are gonna win. They're on the $35^{\text {th }}$ floor? You're gonna be on the $50^{\text {th }}$ floor. You're gonna be looking down on them. And the higher you rise, the more they're gonna hate you. Good. Good. Rub their noses in it. Make them suffer. You don't matter all that much to them - so what? So what. Screw them. Remember: the winner takes it all. (Better Call Saul, 2015-present, 'Winner')

In the beat, Jimmy's speech switches affective register from consoling compassion to compassionate motivation. Just moments earlier, he had addressed his colleagues with the same conviction. 'Esposito, that's the shoplifter?', a fellow lawyer enquired. 'The shoplifter. Right. That's right' Jimmy had contended, with an appropriately wry response, before challenging his colleagues to 'take another look' at Christy's application. 'It's really good', he opined. But compassion is not enough to convince his colleagues, and just moments after Jimmy addresses Christy, we witness the limits of compassion as Jimmy himself crashes and burns. Jimmy's failure to pass his bar reinstatement hearing radiates with 'the painfulness of misrecognition' (Cefai, 2012: 73) that haunts his character. No matter his ingenuity, Jimmy repeatedly fails to be deemed worthy of respect by the more mediocre characters he outwits. While he gives off the appearance of abiding by the mediocrity of his peers, they do not recognise him as being one of them.

Thinking to the roots of the term humiliation in 'humility' and 'humble', from the Latin humilis meaning 'low' and 'lowly', from humus meaning 'ground' (Oxford English Dictionary, 2018), to spoil or 'soil' an identity is to lower a subject's social status. Cultural notions of status such as 'one-upmanship', 'tall poppy syndrome' and the 'put-down' encapsulate this articulation of social hierarchy by the spoiling of identity. In this scene and many others, the spoiling of identity occurs by activating differences in power. These differences are coded as discrepancies in social status - who sits at which table and with what influence; who is a decision-maker and who is an applicant; whose experience aligns with the consensus. Individualising notions of 'winning' and 'losing' offer neat condensations of 'the pervasive inequality and competition that underpins the growth of the new creative economy' (McRobbie, 2015: 13). These notions are 'impressions' of success or failure - they impress upon us an idea about desire, such as the desirability of being 'on top', 'inside' or even, 'an outsider'. We might think of reputations as relational surfaces 
- particular impressions made by 'the very affect of one surface upon another' (Ahmed, 2004: 6). We can see the affective impressions of status worked aesthetically, in literary devices such as irony, or narrative tropes like the heroic underdog.

Writer and creator of the Channel 4/Netflix series Black Mirror (2011-present), Charlie Brooker, singles out the episode 'Hated in the Nation' as having been inspired by Ronson's So You've Been Shamed (Hibberd, 2018). Like Better Call Saul, Black Mirror evokes humiliation as a central narrative theme across many episodes. In 'Hated in the Nation', people are punished for using a hate-filled hashtag on a Twitter-like platform. A character explains, 'It's a hashtag game, you know, like "death to . .."You insert the name of someone who's being an arsehole. It's not real. It's a joke thing'. But \#DeathTo turns out to be no joke, as users of the hashtag are targeted for retribution. The episode exaggerates the discrepancy between the surface impressions that generate and draw people into a 'hashtag game' - the game of humiliation - and the severity of its implications. This discrepancy results from the gamifying of humiliation on platform media known as 'e-bile', in which 'a pleasurable - albeit competitive - game' of competing to produce 'the most creative venom' creates 'feelings of irritation, anxiety, sadness, loneliness, vulnerability, and unsafeness; to feelings of distress, pain, shock, fear, terror, devastation, and violation' in those 'who have been targeted' (Jane, 2014: 356). 'Shut Up and Dance' further probes the power of social media to bring someone down. The anonymity of the Internet, in combination with the tabloid culture of social media (sensationalism and morality), allow sexual misconduct to become weaponised (see Kipnis, 2017). The episode focuses on the intense drama of shame, fear and panic that follows being 'found out' by some unknown person or group of persons. Operating in secret like the hacker organisation Anonymous, the extortionists threaten to upload video recordings of the protagonists engaging in morally compromising activities, such as masturbating with the aid of illegal images. Rather than extort money or material possessions, the activists extort a moral lesson - their game demonstrates the lengths that people will go to avoid their humiliation, highlighting how concern about others flips into self-preservation. Also consider how 'White Bear' stages the media spectacle of public shaming. In this episode's version of reality TV, the concept of the immersive 'viewer experience' is taken beyond existing norms of production, as the audience actively participates in humiliating those deemed deserving of such punishment. The fact that, sociologically, the targets of online hostility are largely women (Jane, 2014), is a point to which I return later.

Exploring how the governance of social exclusion is implicated in automation, 'Nosedive' picks up on the direction of travel we see in the rise of the trillion-dollar industry in data. The downfall of the protagonist whose social faux pas leads to a downwards spiral of decision-making that contravenes socially acceptable standards of behaviour points to the horrors of a fully automated criminalisation of social exclusion. This is a vision of an automated humiliation that turns humiliation from a disciplinary power into a biopolitics. This could be taken as a fictionalisation of the scenario playing out in China's Social Credit System, or India's biometric registration project for the distribution of food security and other welfare entitlements, Aadhaar. The automation within such projects can compound inequality, exacerbate the punitive efficiency of moral policing and persecution and introduce new obstacles to social justice (Arora, 2019). We 
could consider too Australia's automation of the Centrelink benefits system, where an algorithmic flaw resulted in tens of thousands of welfare recipients being wrongly billed for welfare debt - 'robo-debt', as it was aptly named (Terzis, 2017). The mediation of humiliation by a national media culture is the focus of the very first episode of the series. 'The National Anthem' situates humiliation within the genre of political drama, as the ultimate challenge to power. The episode asks whether a figure of power, such as the British Prime Minister, could endure the humiliation of his own bestiality being televised live 'to the nation' (and, the audience learns, he can). Humiliation is a way of staging the question of what people can tolerate.

As this introductory discussion suggests, Black Mirror picks up on the centrality of humiliation to stories of the human-technology relation. The incitement to humiliate has become part of the way we live with digital media technologies within an 'economy of visibility' (Banet-Weiser, 2018): humiliation as a political strategy (showing someone up; bringing someone down) resonates with a social media culture in which the activity of cultivating and registering status has become prolific. Networked technologies 'operating on nonconscious, bodily responses or affect' and 'flooding the domain of connectivity with other-than-human agencies or datafication' (Clough, 2018: ix) open new domains of power among governments, corporations and self-governing subjects. The Cambridge Analytica scandal, of mobilising downfall through accusatory messaging that targeted individuals based on their data profiles, and without their knowledge, is a case in point. As are all the various instances of harassing and denigrating women on the platforms Reddit.com and 4chan, whose 'assemblage of design, policies, and norms' encourages 'toxic technocultures' (Massanari, 2015: 336). Automation, the result of human and non-human agents interacting, extends humiliation's scope and scale. The 'speeds of the territorialization, deterritorialization, and reterritorialization of social spaces, as well as the adjustment to the vulnerabilities of exposure to media event-ness, are beyond any user's mere decision to turn "it" on or off' (Clough, 2000: 3). This decentring of the human as the seat of social action might have the effect of augmenting humiliation's 'historical sensorium' (Berlant, 2011: 3). Humiliation foregrounds the vulnerability of human dignity to the injuries of a technologised semiocapitalism that downgrades or eradicates all kinds of manual, administrative and service sector work. Humiliation is mediated not only by identificatory notions and categories but, en masse, by governments, corporations and their informatics - a predicament shaped by a whole social scene of techno-mediated transformation that threatens to semi-automate this degradation. As such, the fate of a single character's humiliation articulates humiliation's social force as a force of neoliberalism. Television hence narrates humiliation in this way, as a 'structure of feeling' (Williams, 1977) - as a mediation of 'a collectively held generational historical sense of social relationality' (Berlant, 2015: 199).

The cultural economy of reputation is at once substantiated and promulgated by social media (e.g. Marwick, 2013) - a repercussion of the personalised user profile that demands constant engagement in the task of making impressions in a neoliberal consumer culture wedded to the individual. As we are increasingly interpellated into social experience via a performative individual and collective identity online (Papacharissi, 2011), the 'optimal balance between disclosure and privacy' (Papacharissi and Gibson, 2011: 78) is thrown out of whack. Beyond our individual control, this balance becomes a matter of 
the ranking algorithms that govern how information appears: algorithms simulate and then intervene in the social field, shaping the conditions of representation that determine how the user is 'recognized as a subject with a voice' - such as in the case of the old Facebook EdgeRank algorithm (Bucher, 2012: 1165) or more shrewdly, Reddit's 'point total' based on 'some variation on upvotes minus downvotes' (Massanari, 2015: 337). Our declarative performances of this balancing act thus entangle the need for recognition - that much discussed staple of critical identity movements - with the matter of reputation; speaking, or not, becomes a matter of appearances within technologised schemas of visibility. The cultural logic of 'convergence' and its media architecture of 'flow' (Papacharissi, 2011: 305) wed social participation to the performance of an individual subjectivity - our 'difference' (Lash and Lury, 2007: 5) becomes an appearance that might make an impression.

The performance of impressions is mediated not only by media technologies, but by the structures of feeling they collate and disseminate. The social dynamics that networks mediate, such as 'invisible audiences', 'collapsed contexts' and 'the blurring of public and private' (boyd, 2011: 49), consequent to the 'scaling' (p. 48) of content and various other 'affordances of networked publics' (p. 46) distribute a range of social feelings in part by generating impressions. Immersed in an 'algorithmic culture' (Striphas, 2015: 395), subjects must interface and 'face-off' the power differentials that are induced by algorithmic communication that paradoxically combines collective sentiment and social action (such as in voting behaviour) with 'black box' technologies (that conceal the premise of the communicative interface). These relations, among visibility and invisibility, what is known and not, expressed or hidden - the privacy and publicity of data coincide with those that structure shame and humiliation. The everyday anxiety of living with 'something we fear will badly harm our reputation' (Ronson, 2015: 27) is exacerbated by the resonance between the cultural characteristics of humiliation and the ways in which digital media compel us to communicate our individuality online. Anxiety about appearances is hence an important site in the digital mediation of humiliation's affective structure. These anxieties might propel us into competitive scrutiny, assertion or backtracking, as in the case of the YouTube apology video.

Prior to networked communication, William Miller (1993) observed that as 'perhaps our most powerfully socially oriented emotion of self-assessment', humiliation, 'or at least the threat of it', has become 'a normal feature of most routine social interaction' (p. x). The more a neoliberal theory of competition pervades everyday life, and the more we enact this competitive mentality online, the more potent humiliation becomes as a latent force of our social relations. This latent force can be found in the threat of humiliation that is also a pertinent feature of humiliation's structure. As the predicament of Better Call Saul's Christy Esposito illustrates, it is humiliating to be called to interview for a job that does not exist. Moreover, in response, we cannot simply take justice into our own hands: humiliation stages the problem of social action in the face of hypocrisy. What should we do about the façade of power's performance? Every day, a television character says, 'you humiliated me', 'I was humiliated', 'I'm not going to be humiliated any longer' and so on, and news media reports represent people's first person accounts of their humiliation by government policies, whether austerity or the Windrush scandal. The structure of humiliation extends beyond the shaming frenzies of Twitter that 
captured Ronson's and my colleagues' imaginations, or the schadenfreude that is exploited by reality TV (Cross and Littler, 2010; Skeggs and Wood, 2012). There are "clearly identifiable "tactics of humiliation" that are consciously mobilized by a [sic] various actors in a variety of contexts' (Saurette, 2005: 6) - mobilised, and in the era of Facebook, monetised. The seemingly 'conscious decision by the government to humiliate and degrade people', as the film maker Ken Loach put it (Wilkinson, 2017), suggests just such a conscious mobilisation. As do the hallmarks of 'popular misogyny' expressed on the Internet - 'the instrumentalization of women as objects, where women are a means to an end: a systematic devaluing and dehumanizing of women' (Banet-Weiser, 2018: 2).

\section{Humiliation's eventful structure of feeling}

Even the most generic definition of humiliation, as the event of ' $m a k$ [ing] (someone) feel ashamed and foolish by injuring their dignity and pride' (Oxford English Dictionary, 2018), points to a 'complex experience and emotion in which conceptual and cultural expectations and meanings intertwine with powerful affective and bodily forces' (Saurette, 2005: 3). In humiliation, someone is (1) made to feel ashamed; (2) made to feel foolish; and (3) injured (via an injury to dignity, pride, self-worth). Humiliation consists in an elemental structure in which each element relates to the other and, in combination, each acts as a relation of force. Humiliation's shame, the shame of humiliation, is externally imposed and defined, which is in contradistinction to the usual aetiology of shame understood as an internal reflection and affective state that resonates outwards (e.g. Tomkins, 1963; Woodward, 2000). The second element of humiliation is foolishness, also externally imposed and defined. Humiliation's foolishness is stupidity of a particular kind - the bearing out of a lack of cultural capital. The kind of cultural capital that matters most to humiliation, the kind of knowing, the savvy, is that which exploits prejudicial forms of identity (e.g. age, gender, nationality, race and class) (see Woodward, 2000). Foolishness riffs off the status quo of identities to the extent that, as forms of cultural difference expressed as affective knowledges, they are able to articulate the terms of social inclusion. What we do not know can hurt us. The fool is duped; the fool did not know better; the fool did not understand the rules of the game. The fool was 'conned' (Banet-Weiser, 2018: 97).

The third element of humiliation is injury, also of a particular kind. Humiliation's injury is an injury to self-regard. Dignity and pride, and associated conceptions of the self, including self-confidence, self-esteem, self-respect, self-assurance and self-possession among other notions, denote one's relation to one's self via one's relation with others. Humiliation injures this self-relation. As such, humiliation attacks a person's capacity to relate to and be in the world. To have one's self-regard injured in this way, by being made to feel ashamed and foolish of who one is through the imposition of a construction of who one is meant to be, compels one to experience the limits of one's own self-perception. One must reckon with the power of self-perception in relation to the power of others, socially conceived. The operation of a dominant epistemology of perception is a manifestation of disciplinary power. As Michel Foucault (1977) memorably claimed, disciplinary power is wielded through you, in your self-perception - in your 'soul' (p. 33). 
In the structure of humiliation then, one becomes ashamed of their foolishness (foolishness is the object of humiliation's shame) and one is made to feel ashamed by dint of being made to be the fool (foolishness subjectivates the subject of humiliation). The 'truth effects' of humiliation's shameful stupidity are less the effects of an autonomous human agency, and more the result of forces that accumulate and are distributed through institutions, networks and cultures, and increasingly via their 'other-than-human agencies or datafication' (Clough, 2018: ix). Furthermore, we can surmise that the combined feeling and self-evaluation, or 'critical feeling' (Cefai, 2012: 35), that follows becoming vulnerable to an injury of this kind is an embodiment of the reflexive definition of the self as 'responsible for its own value' (Skeggs, 2004: 33). Paradoxically, being made to feel ashamed and foolish for having one's dignity or pride injured calls into question one's own role in their humiliation. Humiliation doubly gives form to the experience of powerlessness: in the first, the feeling of inadequacy (it happened to you), in the second, the fact of the feeling of inadequacy being imposed (it happened to you) - the humiliated must account for their own humiliation by dint of an intractable relationality. The feeling of being ashamed sensitises the subject to their sense of self-responsibility, which, within neoliberalism, is a mode of subjectivity that individualises our responsibility to others. Humiliation's shame thus amplifies the failure of the neoliberal subject's own self-investment, ${ }^{1}$ as well as their affective disattunement to the status quo - the 'normative standard of judgement and aspiration that is deeply embedded and accepted' (Saurette, 2005: 13).

We might consider humiliation, then, as greater than the sum of its parts - the becoming of an affective event. On the one hand, feeling ashamed and foolish are the aftereffects of humiliation; the event of humiliation having occurred. On the other, one could not have been humiliated had they not been made to be the fool, in which case, foolishness precedes humiliation. This paradoxical temporality or 'double movement' is made possible, to invoke a Deleuzian concept, by 'the event of the body's own doubling' (Colebrook, 2000: 78). Humiliation bears out a subject becoming-other in relation to its own image. Then again, humiliation marks a traumatic break in the subject's ongoing process of becoming-other, cutting (into) the habitual affectivity of their social participation. Humiliation's eventful structure is therefore characterised by a potent mix of breakage and continuity - humiliation's event is one of a temporal schism that separates out a 'before' and an 'after', as irreconcilable but nonetheless connected senses of self held in tension within the flow of experience. The 'unmasking of pretensions' in view of 'a larger audience' (Saurette, 2005: 12) is retroactive and anticipatory, splicing the before from the after, marking out a dwelling in the 'crisis' of what has happened and in an impossible but inevitable 'ongoingness' (Berlant, 2011: 60).

The temporal schism of humiliation also occurs as an aesthetic rupture brought on by the manipulation of certain aesthetic distinctions that are linked to social standing. The distinctions between 'high' and 'low', 'visible' and 'invisible', 'knowing' and 'unknowing', 'public' and 'private' are those by which shame, foolishness and injury appear. Shame invokes notions of exposure, vulnerability, susceptibility, contagion, faciality, eye contact, skin ${ }^{2}$ and the status quo (Gibbs, 2001; Probyn, 2005), alone pointing to shame as the affect that has been most linked to our social obligation to the feelings of others (Povinelli, 2002). Foolishness invokes the relation between 
knowledge and stupidity, impulsivity, lack (of judgement), triviality, nonsense, insincerity (vs. seriousness), the joke, a deficit (in cultural capital). Whereas injury invokes the wound, silence, voicelessness and the carrying of secrets; being downtrodden, robbed and ground down. This aesthetics of social hierarchy, morality and belonging is incorporated into and managed by institutions, networks and media cultures, generating norms of social inclusion. The affective event of humiliation therefore has variable but predictable cultural characteristics.

\section{The Clinton affair: reputation and the persistence of social value}

I lost my sense of self. (Monica Lewinsky, On the Internet's Reputation Shredder)

As a structure of feeling, humiliation is an emergent social propensity that works our cultural aesthetics of social relating, 'saturating atmospheres of held but inexplicit knowledge' (Berlant, 2015: 194). This does not mean that humiliation is 'new', but that in venting the excesses of social relations in flux - in 'disturbance' (Berlant, 2015: 194) - its affective structure has become prescient. In the example I discuss here, humiliation works the aesthetics of social relating in the service of patriarchal gender relations, reproducing women's social subordination by turning on their capacity for self-abnegation. This type of abnegation, as discussed, is the outcome/coming in of humiliation.

In 2014, Monica Lewinsky herself reminded us that her story, published online on 21 January 1998 in the Drudge Report (www.drudgereport.com), was the first to break the Internet - despite the fact that the Internet was back then 'a perk' even for major news organisations in the United States (Susan Glasser in Harris, 2018). It was, Lewinsky (2014) said, 'the first time you missed history being made if you didn't have access to the Internet'. To return to the theme of public shaming online, Lewinsky cites the media culture of humiliation as the motivation for her public talks: 'cyber bullying, trolling, some forms of hacking, online harassment', she observes, 'all have humiliation at their core' (Lewinsky, 2015). 'There is a very personal price to humiliation, and the growth of the Internet has jacked up that price . . . Cruelty to others is nothing new, but online, technologically enhanced shaming is amplified, uncontained, and permanently accessible' (Lewinsky, 2015). That Lewinsky is the subject of a spoiled identity is plain to see - during her first video-recorded and platformed talk, her chin is tight and trembling, suggestive of the effort of her composure (Lewinsky, 2014). As I watch for the first time, I feel us both on the cusp of faltering: I feel that simultaneous requirement and impossibility of containing something - the mistake, so much bigger than you, and yet so engulfing of you, as it is imposed upon you. 'Humiliation', Miller (1993) writes, 'is the price we pay for not knowing how others see us' (p. x). 'I was threatened with 27 years in jail', Lewinsky recalls, emphasising the frightening prospect of freedom denied. She describes herself as being almost 'humiliated to death'. Lewinsky outlines that price. Lewinsky's parents had her on suicide watch. Lewinsky's is the story of what it is like to be 'Hated in the Nation' (Black Mirror, 2011-present).

The shortcomings of Lewinsky's strategy of survival are particularly revealing of humiliation's social mechanism. Lewinsky's strategy that she self-identifies in a range of 
talks was to distinguish between the 'two Monica Lewinskys': 'me' and 'public Monica Lewinsky . . . constructed with a little fact and a lot of fiction'. By her own account, Lewinsky distinguished as much as she could her own sense of self from the impression of her held by others. She recalls her efforts to delaminate herself - who she (thinks she) is - from 'Monica' she was becoming known as - her reputation. However, the social embedding of her sense of self within the protective milieu of family and friends offered little defence against the 'image of strangers reading the report' that 'amplified by a thousand-fold the shame and humiliation' she felt. Lewinsky found that her reputation was part of herself: the ruining of her reputation, she claims, 'was a form of identity theft'. Humiliation as a theft of identity, as defamation, undermines the sovereignty of the ideational self. ${ }^{3}$ Affect undermines the abstract - one abstraction supplanted for another, the social transpires as materially real. The underlying social reality of one's sense of self - affective, embodied and constitutive - is under assault in the assault on one's reputation. Humiliation works upon the fold of the social within the self, the impression of the reputation within self-perception. Looking back, Lewinsky tries to distil the entangled threads of her reputation online, her data - for which she never derived any royalties, she jokes - from her flesh and blood self - an entanglement upon which online humiliation pivots, the basis upon which 'the Internet has jacked up that price' (Lewinsky, 2015) of 'not knowing how others see us' (Miller, 1993: x).

So described, humiliation emerges out of the problematic of identity as an exercise of power more generally, and specifically, out of the question of resistance. Resistance to, and in relation to, identity, can be encapsulated as the difficulty of escaping 'binary organizations of asymmetrical power', given how notions such as 'hybridity, syncretism, third space ... are in fact products of " the disjunctive logic" that colonization and Western modernity introduced' (Hall, 1999: 6) . . . implicated in the very diagrams they try to escape' (Grossberg, 2010: 202). If the subject of a spoiled reputation could 'fix' the bad identity herself, or if we could fix it for her, we would no longer need to contend with the power of representation and its incessant binaries; we could in fact abandon the project of identity altogether, and certainly of reputation. For Wendy Brown (1995), this impossibility of doing away with an inherited relation of power underlies 'subjection' and the ressentiment that reinstates 'the terms of domination' (pp. 5, 7). Her concern, that resistance 'is figured by and within rather than externally to the regimes of power it contests' (p. 3), points to the insidiousness of humiliation as an affective intensification of the subject's self-relation within a context of power. Intensifying self-relationality via norms of sociality, humiliation becomes a neoliberal affect par excellence.

In response to the humiliation of her identity, it is not enough for Monica to simply assert: 'That's not me!' As Elizabeth Povinelli (2002) explains, 'the social fact of the feeling of being obliged' to 'moral sense and to reason' are often not consistent: people 'discover that their reasoning and their affect are out of joint' (pp. 4-5). ${ }^{4}$ Humiliation foregrounds Lewinsky's impaled agency in her own process of self-identification, but also the psychic pain of enduring the mal-alignment of her reason and her affect. Humiliation is a malady of the integrity of an embodied subject that cannot be resolved through an intentional negation or integration. We might want to distinguish ourselves from the bad reputation, but it is not a matter entirely in our control - we incorporate standards 'from the wider society' that render us 'intimately alive to what others see as 
his [our] failing' (Goffman, 1963: 7). This incorporation cannot always be tracked or resisted by existing cultural codes. Humiliation works this tension, between 'the sociality of affect' (Berlant, 2016a), and the reckoning of knowing better, or otherwise. Although socially modified, moderated and mediated by cultural forms and technologies - from reason to sentimentality, to the panopticon to the algorithm - we might consider that the power of the social to oblige us is not derivative, but affective. Moral sense, especially the feeling of being obliged, is not exhausted by morality - by the cultural encoding of affect within any given system of representation (such as 'moral knowledge'). It is perhaps because humiliation is predicated upon the sociality of affect-our affective experience of living with attachments to objects and abstractions, including our reflexive attachment to our sense of self - that the question of how to resist or move on from humiliation becomes so difficult. If affective sociality is immanent within social relations, resistance or change must occur therein, from within the inter- and intra-subjective swirl, from emotions to non-conscious bodily movement.

Living in these ironic times, we often precisely do know, reasonably, that the bad reputation is wrong; that, for instance, social values are stratified according to the biases of race, class, sexuality, and gender that are both concrete and abstract systems of knowledge informing the cultural economy of reputation. Yet we cannot entirely override a bad affect with a better education. Myriad examples from the postcolonial, critical race, queer and feminist studies literature attest to this in their evocation and politicisation of the painfulness of misrecognition, the 'break with what is called reality' (Goffman, 1963: 10). Humiliation is particularly linked to the anguish of the schism between reason and affect, the non-sovereignty of the subject of an affective sociality. So while within the eventful structure of humiliation the neoliberal dispositif of the responsible individual is squarely brought into focus, humiliation also attunes us to the social as that which affectively obliges us: in the crisis of experiencing the debris of a spoiled identity, we are sensitised to our affective sociality. Whether or not we are in reasonable agreement with the terms of this attunement, which might work for or against our better judgement, they do, nevertheless, pull us into social relating.

\section{Towards a theory of humiliation's media cultures}

Even as we seek to redress the pain and humiliation consequent to historical deprivation of freedom in a putatively 'free' political order, might we thus sustain the psychic residues of these histories as the animus of political institutions constitutive of our future? (Wendy Brown, States of Injury)

A confidence game is one in which a person swindles or robs another person after gaining their confidence. (Sarah Banet-Weiser, Popular Feminism and Popular Misogyny)

We are, of course, socially obliged all the time: this obligation enables us to live $a$ life. However, the scenarios I have discussed in this article - including in the examples of Better Call Saul, Black Mirror and 'the Clinton affair' - illustrate how our affective obligation to the social becomes palpable as a threshold for humiliation. More specifically, I have suggested that affective obligation in the form of reputation has become a pre-eminent threshold. That is, just as reputation has become a primary means by which our affective obligation is made intelligible, reputation in turn has become a prime opportunity for our 
sense of belonging and place in the world to be thwarted. In an earlier moment in feminist theory, Wendy Brown (1995) worries that the historical residues of pain and humiliation, so essential to the 20th-century mobilisation for social justice, will come to entrap future politics within existing, dialectical frames. Her worry could not be more prescient to the theorisation of humiliation's digital media cultures, in which the insidious nature of power goes hand in hand with the mediated expansion of reputation.

Reputation, a long-time necessity of social life allied to social segregation, class distinction, and other forms of social differentiation, has become the focal point for entirely new forms of social relating. Operating within communicative capitalism as a mechanism of 'displacement' (Dean, 2005: 64), social media have spread the activity of reputation from the embodied habitus of identity in the everyday to online communications in which 'people are apt to express intense emotions, intimate feelings, some of the more secret or significant aspects of their sense of who they are' (p. 60, my emphasis). As Jodi Dean explains, by believing that circulating content takes effect, online communication redirects subjective action towards a perceived social that is highly mediated by communicative capitalism. This 'subjective registration effect' (p. 60), the mediated sense that we are acting upon the world - and upon ourselves within it - renders our reflexive sense of world-self-relation susceptible to all the noise of capitalism's mediation. More than threatening to 'spoil' a public identity, humiliation looms large within the ecology of perception that constitutes the very sensibility of what it feels like to be alive, as Williams (1977) would have put it, at this particular historical moment. The feeling of being obliged, and alive, extends beyond any individual person or character's actions, to the social relations and abstractions they manifest. The abstractions of humiliation include the fantasy of 'the global', heard in the celebrity refrain 'the whole world knows'. Explored in this article in the aforementioned examples, and flagged by Ronson's (2015) study of public shaming, this inflation of self-importance is the reputational refrain of social media. This fantasy of 'the global that networked communications produce' is also, as Dean (2005: 69) tells us, pivotal to the foreclosure of politics.

When, as feminist scholars, we find ourselves on the wrong side of the affective obligation of the social, we get caught in the mediation of the expansiveness of the self and the implications of this mediation for politics. As illustrated in my discussion of Lewinsky, the gendering of humiliation is especially apparent where women's confidence is at stake, such as in the neoliberal workplace (McRobbie, 2015) or heterosexual 'hook-up' culture (Cefai, 2018). Humiliation is gendered in the affects that cluster, or do not, around the confidence someone has to be in this world. Such clustering is illustrated in the way that the discursive dynamic between popular feminism and popular misogyny plays out in investments in 'confidence' as both an 'injury (a loss of confidence) and a capacity (a recuperation of confidence)’ (Banet-Weiser, 2018: 93). Camilla Møhring Reestorff (2019) recalls how, reading negative comments in relation to her work on the media backlash against \#MeToo, her affect swung from 'long-term pulsations of despair' (p. iii) to 'the repetitiveness of the anger [that] still gets under my skin' (p. xv). Being able to analyse how hostile messages are shaped by the affective refrains of the 'social news' (the remediation of news media by interpersonal media networks) did not remove their power to affect. '[T]he messages got to me . . . I didn't want to let it affect me. But. It. Did' (p. xiv), she writes - reason and affect, out of joint. 
Research shows that women do not easily speak about the experience of being affected by e-bile (Jane, 2014) - to which we could add 'catfishing' (adopting an online persona to mislead someone), 'revenge porn' (the non-consensual sharing of private sexual materials with intent to cause distress) and other conventions that aim to embarrass. It is as if, given precisely the highly mediated conditions of online communication, we should not be affected as we are by the message. Emma A. Jane (2014) recounts how women become embroiled in a 'tyranny of silence ... hesitant to admit finding such discourse unsettling', not wanting to be perceived as being 'weak or thin-skinned' (p. 356). The experience of being affected by that which only 'subjectively registers' (Dean, 2005) is shamed; in the parlance of humiliation, rendered illegitimate, put down, dismissed. Humiliation is a structure of impunity emboldened by the way that networked content erases the possibility of reply. ${ }^{5}$ With so much more to be said, we can at this point conclude that digital media cultures exacerbate the disconnect between reason and affect that structures humiliation, and that this exacerbation amplifies humiliation's structure. ${ }^{6}$ Humiliation is not only 'consciously mobilized' (Saurette, 2005: 6) but felt out by a system in which the massification of the user profile multiplies a singularity of feeling.

\section{Acknowledgements}

Thank you to Michael Richardson for an invitation to develop this work for a seminar at the University of New South Wales, as well as to participants in the 'Humiliation' conference stream for CAPACIOUS: Affect Inquiry/Making Space at Millersville University. Thank you also to Harry Dyer and Zoetanya Sujon, for their editorial guidance, and for organising Understanding the Social in a Digital Age at the University of East Anglia. I would also like to thank the two anonymous reviewers for their comments.

\section{Funding}

The author(s) received no financial support for the research, authorship and/or publication of this article.

\section{ORCID iD}

Sarah Cefai (iD) https://orcid.org/0000-0001-5283-0442

\section{Notes}

1. Thanks to Sean Cubitt for this point.

2. Silvan Tomkins writes specifically about the role of eye contact and the appearance of the blush on skin in the bodily schema of the shame response. As 'the most reflexive of the affects', shame appears in the face 'because the self lives in the face' (Tomkins in Sedgwick and Frank, 1995: 136).

3. By 'sovereignty', I refer to the work of Lauren Berlant and Lee Edelman (2014), who identify sovereignty as a presumption of the discourse on the subject. Importantly, the ideational concept of sovereign subjectivity is confounded by our 'experience of relation' (viii-ix), linked in particular to what is threatening in sex. The broader context of Berlant and Edelman's critique, an examination of optimism, might point us to the link between humiliation and optimism: it is our hope for the regard of the other, and for our own prevailing sense of self, that structures our vulnerability to the injury of humiliation. 
4. In Povinelli's example, the disconnect between reason and affect is linked to the quandary of multiculturalism - a policy that seeks to embrace 'cultural diversity' while only selectively avowing certain affective social bonds.

5. For more on this argument, see Dean (2005).

6. This is a pattern that we see replicated in cultural politics more broadly. I am thinking of the centrality of humour, play and lack of seriousness in the alt-right - what journalist Jason Wilson (2019) calls the 'jokey, ironic lingo' of the 'chan-driven culture of the new global fascism' - versus the unfashionability of irony in intellectual life, at least in the United States (Kipnis, 2017): both forms of politics diminish rational discourse in favour of the 'capaciousness of affect' (Seigworth, 2017; see also Berlant, 2016b).

\section{References}

Ahmed S (2004) The Cultural Politics of Emotion. Edinburgh: Edinburgh University Press.

Arora P (2019) Benign dataveillance? Examining novel data-driven governance systems in India and China. First Monday 24(2). Available at: https://firstmonday.org/ojs/index.php/fm/article/view/9840

Banet-Weiser S (2018) Empowered: Popular Feminism and Popular Misogyny. Durham, NC; London: Duke University Press.

Berlant L (2008) Thinking about feeling historical. Emotion, Space and Society 1(1): 4-9.

Berlant L (2011) Cruel Optimism. Durham, NC; London: Duke University Press.

Berlant L (2015) Structures of unfeeling: mysterious skin. International Journal of Politics, Culture, and Society 28(3): 191-213.

Berlant L (2016a) Interview with Lauren Berlant. Summer School for Sexualities, Culture and Politics, Research Center for Cultures, Politics and Identities (IPAK.Center), 28 November. Available at: https://www.youtube.com/watch?v=Ih4rkMSjmjs\&fbclid=IwAR28oILk7AT_ JUuz8EciVKMHeylleoOMV12Fu0Q-m-i48oEQisqGVsXfN1o (accessed 10 November 2018).

Berlant L (2016b) Trump, or political emotions. The New Inquiry, 5 August. Available at: https:// thenewinquiry.com/trump-or-political-emotions/ (accessed 6 August 2016).

Berlant L and Edelman L (2014) Sex, or the Unbearable. Durham, NC; London: Duke University Press.

Better Call Saul (2015-present) [TV series] Netflix. Created by Vince Gilligan and Peter Gould.

Black Mirror (2011-present) [TV series] Channel 4/Netflix. Created by Charlie Brooker.

boyd d (2011) Social network sites as networked publics: affordances, dynamics and implications. In: Papacharissi Z (ed.) A Networked Self: Identity, Community, and Culture on Social Network Sites. New York; London: Routledge, pp. 39-58.

Brown W (1995) States of Injury: Power and Freedom in Late Modernity. Princeton, NJ: Princeton University Press.

Brown W (2015) Undoing the Demos: Neoliberalism's Stealth Revolution. Cambridge, MA; London: Zone Books.

Bucher T (2012) Want to be on the top? Algorithmic power and the threat of invisibility on Facebook. New Media \& Society 17(7): 1164-1180.

Burton N (2014) The psychology of humiliation: what is humiliation and can it ever be justified? Psychology Today, 27 August. Available at: https://www.psychologytoday.com/au/blog/ hide-and-seek/201408/the-psychology-humiliation (accessed 10 February 2018).

Cefai S (2012) Critical feelings: A genealogy of knowing feeling in queer feminism. PhD Thesis, University of Sydney, Sydney, NSW, Australia.

Cefai S (2018) The humiliation of 'sex with optimism': fieldnotes from Tinder. Capacious: Journal for Emerging Affect Inquiry 1(3): 104-122. 
Clough PT (2000) Autoaffection: Unconscious Thought in the Age of Teletechnology. Minneapolis, MN; London: University of Minnesota Press.

Clough PT (2018) The User Unconscious: On Affect, Media, and Measure. Minneapolis, MN; London: University of Minnesota Press.

Colebrook C (2000) From radical representations to corporeal becomings: the feminist philosophy of Llyod, Grosz, and Gatens. Hypatia 15(2): 76-93.

Cross S and Littler J (2010) Celebrity and schadenfreude: the cultural economy of fame in freefall. Celebrity Studies 24(3): 395-417.

Dean J (2005) Communicative capitalism: circulation and the foreclosure of politics. Cultural Politics 1(1): 51-74.

European Space Agency (2014) Rosetta scientist Dr Matt Taylor breaks down during apology for 'offensive' shirt: video. The Guardian, 14 November. Available at: https://www.theguardian. $\mathrm{com} / \mathrm{science} / \mathrm{video} / 2014 /$ nov/14/rosetta-scientist-matt-taylor-breaks-down-apology-offensive-shirt-video (accessed 26 February 2019).

Foucault M (1977) Discipline and Punish: The Birth of the Prison. London: Penguin Books.

Gibbs A (2001) Contagious feelings: Pauline Hanson and the epidemiology of affect. Australian Humanities Review 24. Available at: http://australianhumanitiesreview.org/2001/12/01/contagious-feelings-pauline-hanson-and-the-epidemiology-of-affect/

Goffman E (1963) Stigma: Notes on the Management of Spoiled Identity. Englewood Cliffs, NJ: Prentice-Hall, Inc.

Grossberg L (2010) Cultural Studies in the Future Tense. Durham, NC: Duke University Press.

Hall S (1999) Thinking the diaspora. Small Axe6 (September), pp. 1-18.

Harris J (2018) 'Washington was about to explode': the Clinton scandal, 20 years later. Politico Magazine, 21 January. Available at: https://www.politico.com/magazine/story/2018/01/21/ clinton-lewinsky-scandal-20-years-later-me-too-216484 (accessed 23 August 2018).

Hibberd J (2018) Black Mirror showrunner explains season 3 endings. Entertainment Weekly, 12 December. Available at: https://ew.com/article/2016/10/23/black-mirror-postmortem-interview-season-3/ (accessed 21 February 2018).

Jane EA (2014) 'Your a Ugly, Whorish, Slut': understanding e-bile. Feminist Media Studies 14(4): $531-546$.

Kipnis L (2017) Unwanted Advances: Sexual Paranoia Comes to Campus. New York: Harper Collins.

Lash S (2007) Power after hegemony: cultural studies in mutation? Theory, Culture \& Society 24(3): 55-78.

Lash S and Lury C (2007) Global Culture Industry: On the Mediation of Things. Cambridge; Malden, MA: Polity.

Lewinsky M (2014) On the Internet's reputation shredder. Forbes Under 30 Summit, 20 October. Available at: https://www.youtube.com/watch?v=Xy7icJSTjL8 (accessed 24 July 2018).

Lewinsky M (2015) The price of shame. Ted Talks, 20 March. Available at: https://www.youtube. $\mathrm{com} /$ watch? $\mathrm{v}=\mathrm{H}$ 8y0WLm78U (accessed 24 July 2018).

McKie R (2015) Tim Hunt: 'I've been hung out to dry. They haven't even bothered to ask for my side of affairs'. The Guardian, 13 June. Available at: https://www.theguardian.com/science/2015/jun/13/tim-hunt-hung-out-to-dry-interview-mary-collins (accessed 23 June 2019).

McRobbie A (2015) Be Creative: Making a Living in the New Culture Industries. Cambridge; Malden, MA: Polity Press.

Marwick AE (2013) Status Update: Celebrity, Publicity, \& Branding in the Age of Social Media. New Haven, CT; London: Yale University Press.

Massanari A (2015) \#Gamergate and the Fappening: how Reddit's algorithm, governance, and culture support toxic technocultures. New Media \& Society 19(3): 329-346. 
Miller WI (1993) Humiliation. Ithaca, NY: Cornell University Press.

Oxford English Dictionary (2018) Oxford: Oxford University Press.

Papacharissi Z (2011) Conclusion: a networked self. In: Papacharissi Z (ed.) A Networked Self: Identity, Community, and Culture on Social Network Sites. New York; London: Routledge, pp. 304-318.

Papacharissi Z and Gibson PL (2011) Fifteen minutes of privacy: privacy, sociality, and publicity on social networking sites. In: Trepte S and Reinecke L (eds) Privacy Online: Perspectives on Privacy and Self-disclosure in the Social Web. Berlin; Heidelberg: Springer-Verlag, pp. 75-89.

Povinelli E (2002) The Cunning of Recognition: Indigenous Alterities and the Making of Australian Multiculturalism. Durham, NC: Duke University Press.

Probyn E (2005) Blush: Faces of Shame. Minneapolis, MN; London: University of Minnesota Press.

Reestorff CM (2019) Affective politics and involuntary autoethnography: backlashes against \#MeToo. Capacious: Journal for Emerging Affect Inquiry 1(4): ii-xix.

Ronson J (2015) So You've Been Publicly Shamed. New York: Penguin Random House.

Saurette P (2005) The Kantian Imperative: Humiliation, Common Sense, Politics. Toronto, ON, Canada; Buffalo, NY; London: University of Toronto Press.

Sedgwick EK and Frank A (1995) Shame and Its Sisters: The Silvan Tomkins Reader. Durham, NC; London: Duke University Press.

Seigworth GJ (2017) Capaciousness. Capacious: Journal for Emerging Affect Inquiry 1(1): i-v.

Skeggs B (2004) Class, Self, Culture. London; New York: Routledge.

Skeggs B and Wood H (2012) Reacting to Reality Television: Performance, Audience and Value. London, New York: Routledge.

Striphas T (2015) Algorithmic culture. European Journal of Cultural Studies 18(4-5): 395-412.

Terzis G (2017) Austerity is an algorithm. Logic, Issue 3, 1 December. Available at: https://logicmag. io/justice/austerity-is-an-algorithm/ (accessed 2 August 2019).

Tomkins S (1963) Affect-Imagery-Consciousness. Volume II - The Negative Affects. New York: Springer.

Wilkinson A (2017) 'Dare them to censor you': Ken Loach talks art and activism in I, Daniel Blake and Beyond. Vox, 4 January. Available at: https:/www.vox.com/culture/2017/1/4/13980456/ ken-loach-interview-i-daniel-blake-bureaucracy-palme-dor (accessed 31 December 2018).

Williams R (1977) Structures of feeling. In: Williams R (ed.) Marxism and Literature. Oxford: Oxford University Press, pp. 128-135.

Wilson J (2019) Do the Christchurch shootings expose the murderous nature of 'ironic' online fascism? The Guardian, 15 March. Available at: https:/www.theguardian.com/world/commentisfree/2019/mar/15/do-the-christchurch-shootings-expose-the-murderous-nature-ofironic-online-fascism (accessed 15 March 2019).

Woodward K (2000) Traumatic shame: Toni Morrison, televisual culture, and the cultural politics of the emotions. Cultural Critique 46: 210-240.

\section{Author biography}

Sarah Cefai is a lecturer in Gender, Sexuality and Cultural Studies at Goldsmiths, University of London. Sarah's research addresses issues of cultural politics, affective social forms, and the ordinary aesthetic textures of everyday life, particularly with regard to sexuality, intimacy and social belonging. 